\title{
Contexts of Encounter: How and Where to Criticise Art and Science
}

\section{Charlotte Sleigh}

\section{From objects to things}

This pregnant, speckled swell of a shell: this too is art.

Such a claim is preposterous in a modern, secular world. If there is no creator then only humans can make art. A shell is simply a shell, though it may look beautiful to us.

Yet things have been changing recently. Bruno Latour (Politics of Nature) and Donna Haraway have been at the vanguard of scholarship that has raised an appreciation of the role of non-human nature (things, critters) in the making of our world, our science, our technology, our arts. If we take these scholars seriously, then a non-human agent may, after all, create a work of art. However, such a (re)turn towards non-human nature in the networks of making and being is a tricky move, since it can superficially be confused with the attitude of the scientists who believed that certain things were real all along. Thus one is unsure what to make of critic Laura Cumming, who writes of the bower bird in an art-science exhibition: "[he] has a concept of beauty that precedes and governs his creation. It [sic] is by definition an artist" (Cumming "Andy Holden \& Peter Holden").

From a naïve immersion in science-culture, one might be tempted to see the nest, in this instance, as a natural object, devoid of the politics and connoted values that adhere to a human-made artefact. Such being the case, one would have a narrow range of critical tools with which to appraise it, perhaps mainly formalist in nature. Martin Kemp's celebrated writings on science and art, though insightful, stay within these limits. Accepting that a bird can make art may incline us to slacken our critical approach to human-made art, restricting it to a de-politicised range of aesthetic interrogations. Such an implicit naturalising of the products of human creativity would look much like the dull and reactionary move of evolutionary psychology, and though such approaches were fashionable in the early 2000s they appear to be fading away. Latour asserts the opposite hope, expressing his desire that:

... all entities . . cease to be objects . . . and become again things, mediating, assembling, gathering many more folds . . . if this were possible then we could let the critics come ever closer to the matters of concern we cherish, and then at last we could tell them: "Yes, please, touch them, explain them, deploy them". (Latour, "Critique" 248)

Latour, in his essay "Why has critique run out of steam?" fears that this task may be too difficult: "Why can we never discover the same stubbornness, the same solid realism by bringing out the obviously webby, 'thingy' qualities of matters of concern?" (237). Attending to things, Art and Science (A\&S; see Sleigh and Craske "Art and Science in the UK") might be the very practice that is able to tease out and offer up the tangle of politics, care and concern that makes entities look like objects or facts. By making visible and questioning the agencies and actions that have produced it, the artist at once offers the object to the viewer and invites her to unimagine it. Science and Technology Studies (STS) scholars have been trying to do something like this with their narratives, but by their production and re-presentation of science- 
things, artists are perhaps even better equipped for the task, as Kathrin Busch suggests:
. . . scientific claims to truth and objectivity are qualified by artistic reflection. Seen from the viewpoint of art, one might recognize the contingency and fictional quality of knowledge, or the aspects of oppression and exclusion inherent in knowledge structures (2).

A\&S can go further than STS: by creating new and strange hybrids, it can make material the matters of concern that are usually so frustratingly intangible. A selection of such "altered realities" is offered by William Myers in his recent book Bio Art. Examples include Boo Chapple's Swiftian project Consumables (2009) in which mobile phones double as food (114-6), or Angelo Vermeulen's complex "living cybersculptures" (Biomodd, 2007-) in which plant combines with computer, evolving at the mercy of crowd-based decisions (212-5). A\&S offers a praxis-based approach to doing ScienceHumanities, though the means by and extent to which it incorporates and transcends STS requires continued attention.

\section{Where the A\&S things are}

However, the context of the encounter is all. A\&S will be differently experienced and evaluated depending on whether it inhabits a space that is considered scientific, artistic or neutral. The patrons of the space will have particular intentions for the work and the interests it should serve. This will affect the implicit presentation of the material (for example layout or lighting) and its explicit interpretative text. Viewers will absorb all this as well as taking cultural cues from the context itself - whether they are supposed to be in a space of learning, awe, reverence, children, and so on. Of course, A\&S can potentially alter or subvert a space, but this too plays off an awareness of the responses originally scripted by it.

The annual Wellcome Image competition (www.wellcomeimageawards.org), for example, has tended to cultivate pictures that, though visually and technologically impressive, have tended to lack the visual research foundation that would raise them to the level of art. Mounted in science-space, they are merely manifestations of the wow factor in science. (A few of 2017's finalists - Spooky Pooka, Daria Kirpach, Madeleine Kuijper, Sophie McKay Knight - suggest that this situation is beginning to change.) The judges have predominantly come from the world of science, with professional artists or art critics in the minority (author redacted, private communication). Debates about whether Photoshop is cheating are indicative of the naïve level of representational realism (c.f. Edwards) amongst stakeholder viewers (author redacted, private communication). In the space of science, a large and colourful picture with a "however did they get that?" effect will do the job.

The 2013 show Genesis, by photographer Sebastião Salgado, was another example of what happens when a science space hosts interdisciplinary A\&S practice. In the context of the Natural History Museum, Salgado's depiction of "pristine" nature (Hattenstone) complemented the objectivist stance cultivated by a scientific institution; the claim to be able to study nature objectively demands that it be situated in a space untainted by human actions. However, as critics of nature documentaries have frequently observed, this amounts to a kind of eco-porn, and actively suppresses discussion of human effects. The show was, in fact, sponsored by a mining company with an exceptionally poor environmental record (Haines). Moreover, Salgado's 
inclusion of so-called primitive humans amongst his animals also plays out a specific way in a scientific context: a Darwinian claim for the naturalisation of humans against, perhaps, a straw man of creationism. The critical, post-colonial perspective is too familiar to bear repetition here. Art critics reviewed the show sceptically (Cumming, 2013) but other viewers may have followed the unreflective critics of the Metro and the Evening Standard in finding it "powerful" and "dramatic".

An exception to the Guardian's usual rule of thumb (always send a science writer if you can) came with a blog review of Making Nature (Wellcome Collection, 2016-17), written by Jonathan Jones. This usually pugnacious critic offered, by way of account, a dutiful potted history of natural knowledge, rather than a critique of the collected items in the show. He concluded with a remarkable exoneration of science:

Linnaeus, like Hogarth, Stubbs and Watteau, should be a hero to anyone who cares about our planet. ... Science and art look at nature not out of an urge to dominate but a longing to understand.

This is a surprisingly compliant response to science; Jones seemed to have missed entirely the show's extremely affecting video installation The Great Silence (Allora \& Calzadilla 2014) which greeted visitors with a powerful critique of scientific arrogance. Again, it may be the space that explains the response.

Science purports to show us nature, though as numerous STS scholars have shown us, it does not (Sleigh, 2017). Twentieth- and twenty-first century art rarely makes such a claim; it shows us itself. As Magritte explained in La trahison des images (1928-9), "Ceci n'est pas une pipe" - it is a picture of a pipe. So, when A\&S is shown in a science space, are we still (supposedly) being shown nature, or are we being shown art? Is art in an $A \& S$ show, in a science venue, validated because it happens to do the nature-showing work of science? This seems the case with both the Wellcome images and Genesis. Are we, perhaps, titillated by the thought that science could be performed as art, first questioning the objectivity of science through the presentation of artful representation, then scotching such a doubt through the context of display, safely contained within a building of factual knowledge?

Such an asymmetry of demonstration may also explain why it is harder to come up with obvious instances of "science" appearing in art galleries than it is to find "art" in science museums. To show science would be to show a process; the more easily manifested outcomes of science are either nature or technology. Thus, for example, the Electronic Superhighway exhibition at the Whitechapel Gallery (2016) deliberately fetishized the objects of digital technology. An exception to this generalisation was Sarah Craske's recent show Biological Hermeneutics (Chetham's Library, Manchester, 2017), which audaciously presented a new science - the eponymous Biological Hermeneutics - complete with a history of the field and a video of the hybrid practices that constitute its methods. ScienceHumanities is well placed to unpack the strategies of realisation (visual, epistemological, semiotic) employed in such a project, though it may struggle to engage the ludic qualities of art: of what value is a fictional history? Is it merely an illustration of the type of narrative a historian would create with apparently real science? An artist would surely resist such co-option just as much as she would resist co-option into the project of science communication or valorisation.

The recently founded Science Gallery London suggests, in its name, a new and interdisciplinary space where such asymmetries may not obtain. However, its official communications tend to collapse into a hierarchical model of A\&S. They speak of art 
and science "colliding", a choice of verb that invokes the high-prestige physics of CERN; and they eulogise the interdisciplinary process as "experimental", again, a scientific discursive choice for validation. Another vox pop in the video enthuses: "through art it's much easier to explain [science] and it's more engaging".

\section{Making space for $\mathrm{A} \& S$}

Contemporary art, meanwhile, muddies the waters by claiming to constitute its own space through practice rather than architecture. According to Sheikh, contemporary art is frequently seen as "a place 'where things can happen' rather than a thing 'that is in the world"' (Sheikh 193). Art along these lines may be very difficult to exhibit, at least in any conventional sense. Having an artist learn and appropriate laboratory techniques may perhaps be a piece of performance art restricted to the audience of scientists around her. If art has a blind spot in relation to the A\&S project, symmetrical to the lack of self-reflection in scientists, it is that many artists are unconcerned with public communication. Many are uninterested in what the public thinks of their work (private communication). Alas, even training in STS brings its own forms of enculturation which can be obscured by unreflexive practice. Sheikh is amongst the voices still calling for something more radical, expressing a hope for neutral spaces that can escape the layering interpretations of established galleries:

It should be possible to think of educational spaces that are produced through subjectivities rather than merely producers of them. Or put in other words, not just producing artworld artists, but rather positions within as well as without the art world and its repetitious economies of galleries, collectors, markets, careerings, reifications, trends and circuits (Sheikh 196).

What new spaces might be hijacked for A\&S? There are civic spaces, local museums and galleries; festivals and shopping centres. Artangel, a charitable organisation, champions "extraordinary art [in] unexpected places" according to its website, and it may not be coincidental that science is a very strong theme in its productions (Artangel, "Artangel"). The use of unexpected spaces is no guarantee of a criticalinterrogative approach, however. Guerilla Science, for example, has worked with artists on some extraordinary immersive projects at music festivals around the world; yet its shows have been intended to provoke "curiosity" (Sleigh and Craske, "Art and Science in the UK"; Agar), or have presented science as though it has an uncomplicatedly progressive tendency (Sleigh and Craske "Nine-tenths of the iceberg"). Nor are pop-up spaces without controversies of their own; a great deal of Internet commentary on the bower-bird show focuses, quite legitimately, on the closure of the public library that has been repurposed as a temporary gallery to house it.

If uncontaminated spaces - that is, not preassociated with science or art - are not a guarantee of symmetrical and reflexive exhibition, then perhaps we should think about spaces as they are made through curation. Sheikh's definition of art as a place where things happen might provoke us to consider curation - an act of space-making - as a kind of art-research practice in its own right (c.f. O'Neill 87-130), irrespective of the established or unestablished nature of the venue it occupies. Curation is a spatial practice that can restore the self-critical awareness of science, on the one hand, and, on the other, supplement the unwillingness to explicate that sometimes afflicts contemporary art. As Kate Fowle has pointed out, the contemporary curator's 
motivation is "closer to the experimentation and inquiry of artists" practices than to the academic or bureaucratic journey of the traditional curator" (32). She presents a mode of curation that eludes Foucault's model of social-discipline: "a kind of creative 'maintenance,' ... [that] involves supporting the seeds of ideas, sustaining dialogues, forming and reforming opinions, and continuously updating research" (33).

The creative curatorial (mis)use of heavy historical baggage can sometimes be more liberating than the pretence of unencumbered innovation. The Science Museum, London, is most definitely weighed down by its institutional past, but this was exploited creatively and reflexively in its Cosmonauts show (2015-16). Mounted amidst the hoopla of Briton Tim Peake's journey into space, it de-familiarised the iconic designs and the heroic narrative of space by re-presenting it in the Soviet context - despite, or perhaps because, of its history as a place where generations of British families have gone to learn the Glorious Story of (British) Science (Morris). Strangely enough, thanks to the construction of the Science Gallery, the Wellcome Collection begins to look like an established space that can creatively interrogate its own traditions. Its recent shows Making Nature and Electricity have been particularly strong, succeeding in presenting something much more multi-vocal than earlier, more didactic exhibitions.

Cumming's words about the bower-bird artist and the concept of beauty in the opening paragraph of this article are drawn from her review of a show put together by an ornithologist father and his artist son. Entitled Natural Selection, it was on show at the former Newington Library, London, in 2017. Both the curation of the show and Cumming's review of it are exemplary of Fowles' ideal. Though Cumming attributes "art" to the bird participants, she also draws attention to the quality of "artfulness" exhibited by the show's human makers. What looks like a real collection of eggs is, as closer inspection reveals, ceramic. Attention is drawn to the labour of science; what, in fact, is the work of science but artfulness? Answering this question may be the work of the ScienceHumanities, and may well necessitate transdisciplinary working with artists. 


\section{Works Cited}

Agar, Jon. "The curious history of curiosity-driven research." Notes and Records: The Royal Society Journal of the History of Science, vol. 71, no. 4, 2017, pp. 409429.

Artangel. "Artangel," www.artangel.org.uk/. Accessed 4 Dec. 2017.

Cumming, Laura. "Sebastião Salgado: Genesis - Review." The Observer, 14 Apr. 2013. www.theguardian.com/artanddesign/2013/apr/14/sebastiao-salgadogenesis-review. Accessed 11 Dec. 2017.

---. "Andy Holden \& Peter Holden: Natural Selection Review - Artfulness is Eggshaped." The Observer, $10 \quad$ Sep. 2017. www.theguardian.com/artanddesign/2017/sep/10/natural-selection-andy-peterholden-artangel-newington-library-review. Accessed 11 Dec. 2017.

Edwards, Steve. Photography: A Very Short Introduction. Oxford UP, 2006.

"Engaging with the Science Gallery London." Youtube, uploaded by Science Gallery London, 24 Jan. 2017, youtu.be/DKCvzHrFSvM. Accessed 11 Dec. 2017.

Fowle, Kate. "Who Cares? Understanding the Role of the Curator Today." Cautionary Tales: Critical Curating, edited by Stephen Rand and Heather Kouris, apexart, 2007 pp. 26-35.

Haines, Gavin. "The Natural World, Photographed by Sebastião Salgado - Sponsored by a Corporation that's Despoiling the Amazon." The Independent, 17 July 2013. www.independent.co.uk/arts-entertainment/art/news/the-natural-worldphotographed-by-sebasti-o-salgado-sponsored-by-a-corporation-thatsdespoiling-the-8714748.html. Accessed 11 Dec. 2017.

Haraway, Donna. Staying with the Trouble: Making Kin in the Chthulucene. Duke UP, 2016.

Hattenstone, Simon. "In the Beginning." The Guardian, 11 Sep. 2004. www.theguardian.com/artanddesign/2004/sep/11/sebastiaosalgado.photograph y. Accessed 11 Dec. 2017.

Hudson, Mark. "A Truly Mind-Bending Array of Humanoid Imagery - Robots, Science Museum, Review." The Telegraph, 7 Feb. 2017. www.telegraph.co.uk/art/what-to-see/truly-mind-bending-array-humanoidimagery-robots-science-museum/. Accessed 11 Dec. 2017.

Jones, Jonathan. "Our obsession with the Natural World isn't about Power - It's about Love." The Guardian, 2 Dec. 2016. www.theguardian.com/artanddesign/ jonathanjonesblog/2016/dec/02/making-nature-how-we-see-animalswellcome-collection. Accessed 11 Dec. 2017.

Kemp, Martin. Structural Intuitions: Seeing Shapes in Art and Science. U of Virginia P, 2016.

Latour, Bruno. "Why has Critique Run out of Steam? From Matters of Fact to Matters of Concern." Critical Inquiry vol. 30, no. 2, 2004, pp. 225-248.

---. Politics of Nature: How to Bring the Sciences into Democracy. Translated by Catherine Porter, Harvard UP, 2004.

Morris, Peter, editor. Science for the Nation: Perspectives on the History of the Science Museum. Springer, 2016.

Myers, William. Bio Art: Altered Realities. Thames \& Hudson, 2015,

O’Neill, Paul. The Culture of Curating and the Curating of Culture(s). MIT Press, 2012.

Sample, Ian. "Science Museum's robotic delights hold a mirror to human society." The Guardian, 7 Feb. 2017. www.theguardian.com/technology/2017/ 
feb/07/science-museum-london-trove-of-robotic-delights-holds-a-mirror-tohuman-society. Accessed 11 Dec. 2017.

Science Museum Press Office. "Science Museum to Reveal Remarkable 500-Year History of Robots in New Exhibition." Press release 10 May 2016. www.sciencemuseum.org.uk/about-us/press/may-2016/rise-of-the-robots. Accessed 11 Dec. 2017.

Sheikh, Simon. "Spaces for Thinking. Perspectives on the Art Academy." Texte zur Kunst, vol. 62, 2006, pp. 191-196.

Sleigh, Charlotte, and Sarah Craske. "Art and Science in the UK: A Brief History and Critical Reflection." Interdisciplinary Science Reviews, vol. 42 no. 4, forthcoming 2017.

---. "Nine-tenths of the iceberg: research as the unseen component of artists' work." Interalia Magazine, Nov. 2017. www.interaliamag.org/articles/sarah-craskecharlotte-sleigh-nine-tenths-iceberg-research-unseen-component-artists-work/. Accessed 11 Dec. 2017.

Sleigh, Charlotte. "Communicating Science." The Oxford Illustrated History of Science, edited by Iwan Rhys Morus, Oxford UP, 2017. pp. 378-409.

Turk, Victoria. "Science Museum's Robots: Who Is Really Pulling the Strings?" New Scientist website, 13 Feb. 2017. www.newscientist.com/article/2121092science-museums-robots-who-is-really-pulling-the-strings/. Accessed 11 Dec. 2017. Published in shorter form in New Scientist magazine 25 Feb. 2017. 